\title{
Systematic Review of the Effects of Coffee or Its Components on Platelets and Their Regulators
}

\author{
Liliana Sofia da Silva Gache, BSc, ${ }^{1, i}$ Josiana Vaz, BSc, MSc, PhD, ${ }^{1,2, i i}$ \\ and Juliana Almeida-de-Souza, BSc, MSc, PhD ${ }^{1,2, \text { iii }}$
}

\begin{abstract}
Background: Coffee includes some potentially bioactive components that can interfere with platelets, which can influence coagulation, despite generating controversy. The aim of this systematic review is to verify whether coffee or its components can influence platelet regulators and/or aggregation.

Materials and Methods: The research was conducted on July 29, 2021, in PubMed, Scopus, and Web of Science, using the following mesh-terms: (caffeine)) OR (coffee)) AND (platelets). Eligibility criteria were: studies carried out in humans, referring to the effects of coffee consumption, or one of its components, on platelets or their regulators. We exclude in vitro or animal studies, reviews, editorials, and non-English written studies. From a total of 836 publications, 17 articles were included from which we extracted the relationship between coffee consumption and changes in blood platelets and performed a subjective assessment of bias.

Results: Ten articles refer to the non-interference of coffee or its components with platelets, nine affirm results that support the increase in platelet aggregation, and eight articles observe the decrease in platelet aggregation when coffee is consumed. Some articles presented the lack of data regarding the sample collection location, age group, or classification as to the type of study, which is limiting.

Conclusions: The heterogeneity of results makes it difficult to correctly interpret the possible interaction of coffee or its components with platelets or their regulators. For better interpretation, further studies on this topic should be carried out considering the individualization of coffee components, different platelet regulators, and the size of the sample used.
\end{abstract}

Keywords: caffeine, thromboxane B2, adenosine receptors A2A, platelet aggregation

\section{Introduction}

C OFFEE Is a beverage widely consumed worldwide, and it is produced from roasted coffee beans that are extracted and processed by a dry or wet technique. ${ }^{1}$ This drink includes some potentially bioactive components, such as caffeine, diterpenes, and polyphenols, such as chlorogenic acid (CGA), quinides, and lactones. ${ }^{2}$

Caffeine (1,3,7-trimethylxanthine) belongs to the group of methylxanthines, and its absorption occurs in the gastrointestinal tract into the bloodstream. ${ }^{3,4}$ Taking into account its lipophilic properties, it is evenly distributed in all body fluids and all organs. ${ }^{4}$ Caffeine metabolism occurs mainly in the liver, ${ }^{3,5}$ being affected by exogenous and endoge- nous factors. ${ }^{5}$ Excretion occurs predominantly by the renal pathway. ${ }^{4}$ The most common polyphenols in coffee are quinidines, lactones, and CGA, ${ }^{1}$ which exhibit many biological properties, including antibacterial, antioxidant, and anti-inflammatory activity, particularly hypoglycemic, hypolipidemic effects ${ }^{6-8}$ and antiplatelet activity, which may result in cardiovascular protection. ${ }^{9,10}$ The phenolic portion of CGA is named caffeic acid and is available for absorption, almost entirely, in the small intestine, after hydrolysis. ${ }^{11,12}$ Most diterpenes are esterified with different types of fatty acids, ${ }^{13}$ with the main pentacyclic diterpenes being found in coffee, cafestol, and Caveol, ${ }^{2,14}$ which have antioxidant and potentially hyperlipemiant effects, especially on cholesterol plasmatic levels. Cafestol

\footnotetext{
${ }^{1}$ Escola Superior de Saúde com sede no Instituto Politécnico de Bragança, Bragança, Portugal.

${ }^{2}$ Centro de Investigação Montanha (CIMO) com sede no Instituto Politécnico de Bragança, Bragança, Portugal. iORCID ID (https://orcid.org/0000-0003-0367-4257).

ii ORCID ID (https://orcid.org/0000-0002-6989-1169).

iii ORCID ID (https://orcid.org/0000-0002-2578-3684).
} 
has $80 \%$ of the potential for elevating low-density lipoprotein (LDL) and $20 \%$ of the potential for elevating very LDL. ${ }^{15}$

Due to its constitution, coffee contributes toward health benefits, through stimulation of the central nervous system, cardiovascular muscle, respiratory system, as well as diuretic and fatigue reduction. ${ }^{16-18}$ It improves energy levels; improves various aspects of brain function such as memory, mood, alertness, energy levels, reaction times, and general cognitive function; ${ }^{19,20}$ may reduce the risk of mortality and chronic diseases such as cancer and stroke; ${ }^{21,22}$ and reduces the moderate consumption of cardiovascular risk. $^{23}$ The health risks from drinking coffee include adrenal fatigue, irregular heartbeat, and hallucinations; coffee accelerates bone loss, tremors ${ }^{24,25}$ and in high doses it seems to increase the risk of miscarriage during pregnancy. ${ }^{26}$ Overdrinking 28 cups of coffee or more per week increased the probability of dying prematurely by $21 \%,{ }^{27}$ and studies reported that the drinking of boiled coffee is associated with an elevated risk for cardiovascular disease, $^{27,28}$ despite inconsistencies. ${ }^{29}$

Platelets or thrombocytes are derived from cellular fragments of bone marrow precursor megakaryocytes ${ }^{30}$ and are non-nucleated blood components recognized as the primary cells that regulate hemostasis and thrombosis, contributing to blood clotting, among other immunological and inflammatory functions ${ }^{31,32}$ (Fig. 1). Under normal physiological conditions, they circulate in close contact with the endothelial lining of the blood vessel wall $^{33}$; however, as a biological response to changes in the organism (injuries, inflammation/sepsis, among others), ${ }^{34}$ platelets respond to changes in the endothelial cell wall fixing at the lesion site, and originating aggregates of platelets or thrombi ${ }^{33}$ (Fig. 2). Depending on the type of change, to which platelets respond, this platelet adhesion will start the process of primary hemostasis, followed by platelet activation, which is initiated by var- ious stimuli, such as adenosine diphosphate (ADP). ${ }^{35}$ Then there is the secretion of aggregating substances and, finally, platelet aggregation. ${ }^{35}$ Prostanoids are eicosoids, a group to which prostacyclins, prostaglandins, and thromboxanes belong. Among these, prostacyclins, ${ }^{36}$ prostaglandin I2 (PGI2), ${ }^{37}$ and cyclic 3'5'-adenosine monophosphate (cyclic AMP or cAMP) are regulators that have antiplatelet action. On the other hand, thromboxane A2 (TXA2) and thromboxane B2 (TXB2) have aggregating action, ${ }^{36}$ as well as the inhibitor of plasminogen activator type 1 (PAI-1) that can promote the permanence of the fibrin clot inhibiting fibrinolysis. ${ }^{38}$

Methylxanthines, such as caffeine, are non-selective blockers of the adenosine receptor ${ }^{33}$ and act especially on the A2A receptor, specifically expressed in platelets. ${ }^{33,39}$ Regarding platelet aggregation, in vitro studies indicate caffeine as a phosphodiesterase blocker, which blocks the conversion of cAMP into 5-AMP, increasing cAMP, with consequent inhibition of platelet aggregation. ${ }^{33,39,40}$ Some studies have shown that CGA inhibited ADP-induced platelet secretion and aggregation, collagen, arachidonic acid, and thrombin receptor activating peptide and also showed a decrease in platelet adhesion/aggregation and platelet-leukocyte interaction. ${ }^{41}$ However, there are studies whose results have shown that neither coffee ${ }^{42}$ nor caffeine ${ }^{35}$ affected platelet aggregation.

This systematic review article aims at understanding the effect that coffee or its components have on platelets or their regulators, to contribute with scientific information relevant to the understanding of interactions at the health level.

\section{Materials and Methods}

This study is a systematic review of the literature to ascertain the effects of coffee consumption on platelets and

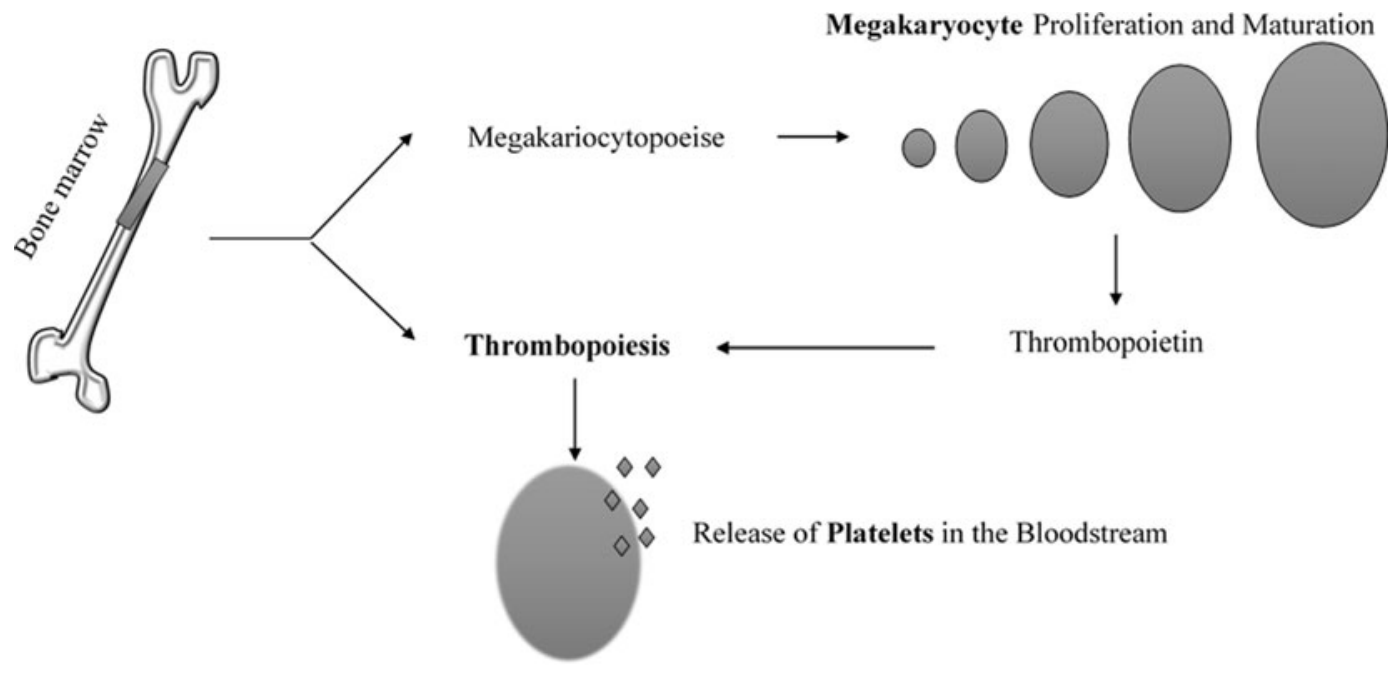

FIG. 1. Platelet formation. 


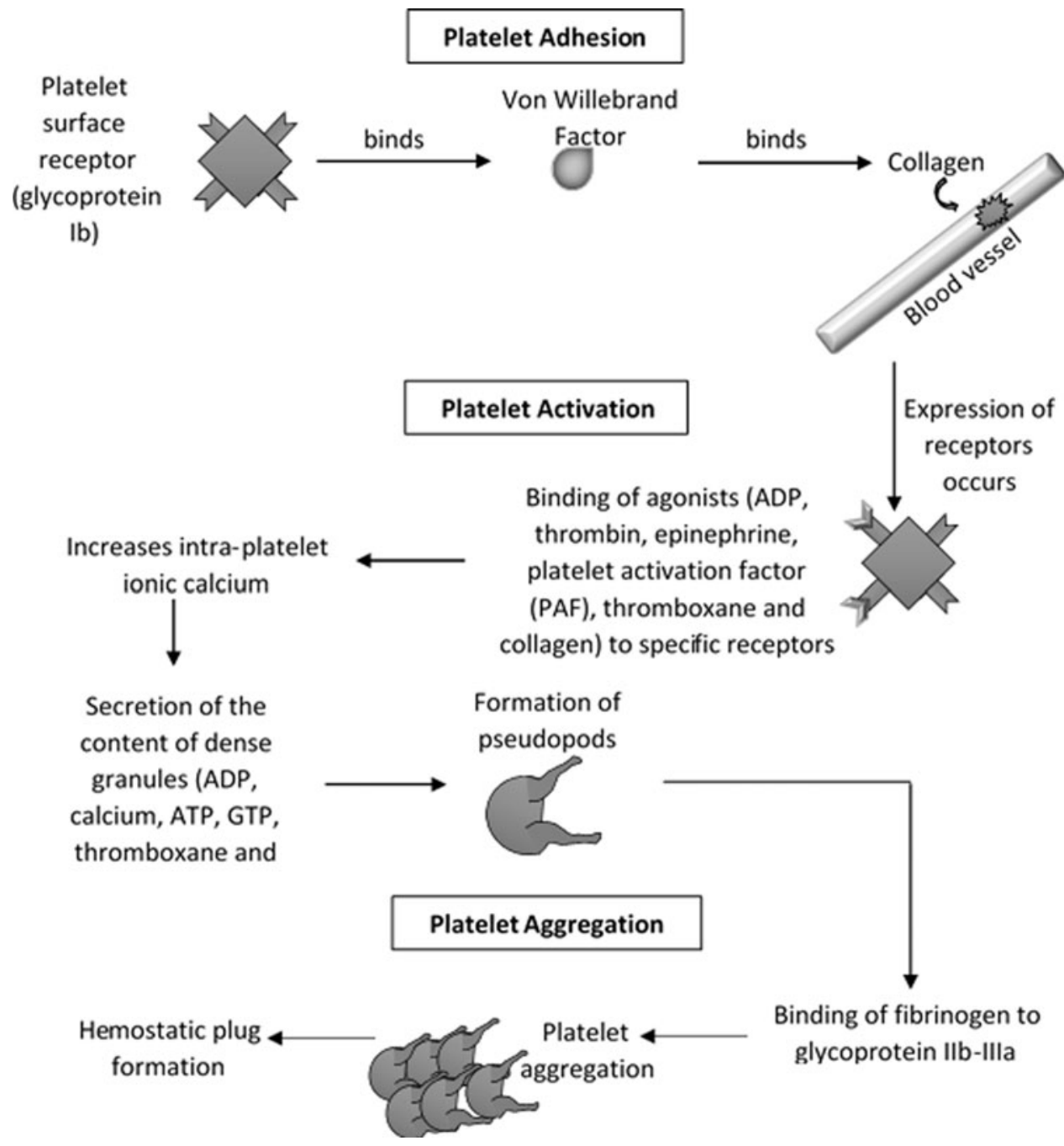

FIG. 2. Platelet metabolism. their regulators and it was prepared according to the PRISMA recommendations, ${ }^{43}$ whose checklist is presented in the Supplementary Data (Supplementary File S1). ${ }^{44}$ These guidelines consist of a flow chart (criteria for identification, screening, eligibility, and inclusion of articles that fall under a review) and a checklist of 27 items. $^{45}$ There is no review protocol registered.

\section{Research question}

A research question was defined according to PICO criteria $^{46}$ : What is the effect of coffee consumption on platelets or on their regulators?

P (Population): Humans.

I (Intervention/Exhibition): Consumption of coffee or its components.

C (Comparation): No/Low consumption of coffee and/or its components (caffeine, diterpenes, CGA).

$\mathrm{O}$ (Evaluation/Outcomes): Blood platelets and/or their regulators $(\mathrm{TxB} 2$, phosphodiesterases (PDE), adenosine receptors, PGI2 and PAI-1).

\section{Eligibility criteria}

For this review, original articles were considered whose studies were carried out in humans, referring to the effects of coffee consumption, or one of its components, on platelets or their regulators.

The exclusion criteria considered were in vitro studies or animal models, as well as review articles, editorials or those written in languages other than English.

\section{Research strategy and descriptors}

The electronic searches were performed independently on July 29, 2021, in PubMed, Scopus, and Web of Science, using the mesh-terms: (caffeine)) OR (coffee)) AND (platelets). Detailed information is presented in Supplementary Data (Supplementary File S2).

\section{Screening and selection of studies}

This search resulted in a total of 836 publications found. After eliminating 306 duplicates, a total of 530 publications were screened. A total of 143 studies were 
considered eligible, and 17 were included in this review. The flowchart ${ }^{47}$ demonstrates the detailed selection process (Fig. 3).

\section{Study tabulation}

To summarize the studies included in this review, Table 1 highlights the most important characteristics. Data depicted: author, year and reference, sample collection location, sample characteristics (size, gender and age, body mass index), study design (duration, coffee or its components, platelets or their regulators), conclusions (relationship between coffee consumption and blood platelets), and classification of possible bias.

\section{Results}

We included 17 experimental studies in this systematic review article, classified into randomized controlled trials, ${ }^{48-50}$ self-controlled trials, ${ }^{39,40,51-56}$ and crossover trials ${ }^{57-60}$ and two studies are apparently parallel trials. ${ }^{42,61}$ Only three studies referred to the sample collec- tion site, which was at the University of Kaiserslautern in Germany, ${ }^{60}$ University of California at Davis, ${ }^{61}$ and with members of a Department of Nutrition. ${ }^{50}$ The sample size of the studies is variable, with 3 studies covering 8 individuals, ${ }^{51,55,59} 1$ study covering $9,{ }^{39} 2$ studies using 10 individuals, ${ }^{57,60}$ another 2 involving 12 people, ${ }^{42,52}$ 2 articles mentioning 13 participants, ${ }^{40,54}$ only 1 using a sample of 14 people, ${ }^{56}$ one betting on a sample of 20 individuals, ${ }^{50}$ another 2 using $26^{49}$ and 27 people, ${ }^{53}$ respectively, one study collecting a sample of 31 people, ${ }^{61}$ and 2 studies encompassing a larger sample size with $45^{48}$ and 84 individuals, ${ }^{58}$ respectively (Table 1 ).

To perform a qualitative analysis, through a bias analysis, ${ }^{62}$ seven articles ${ }^{40,42,49-51,54,59}$ may present a nondifferential bad classification bias, since they do not detect a relationship between the studied variables. Two articles may present bias in social desirability ${ }^{57,59}$ insofar as the recruited individuals may claim moderate consumption of coffee, as they consider it the most correct, and do not correspond to reality. Three articles present a loss of follow-up bias, either by correspondence to
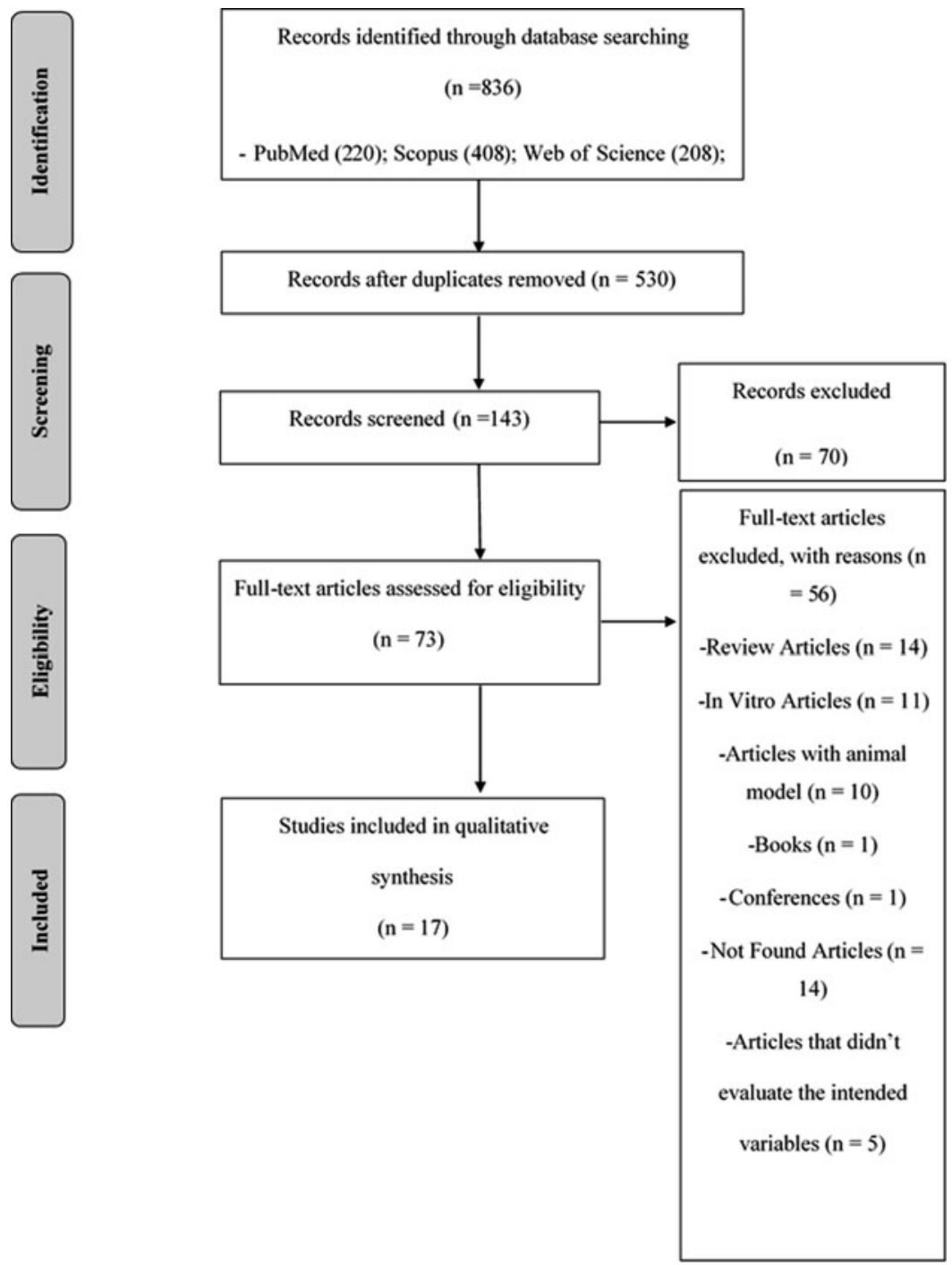

FIG. 3. Flowchart of screening and selection of the studies. 


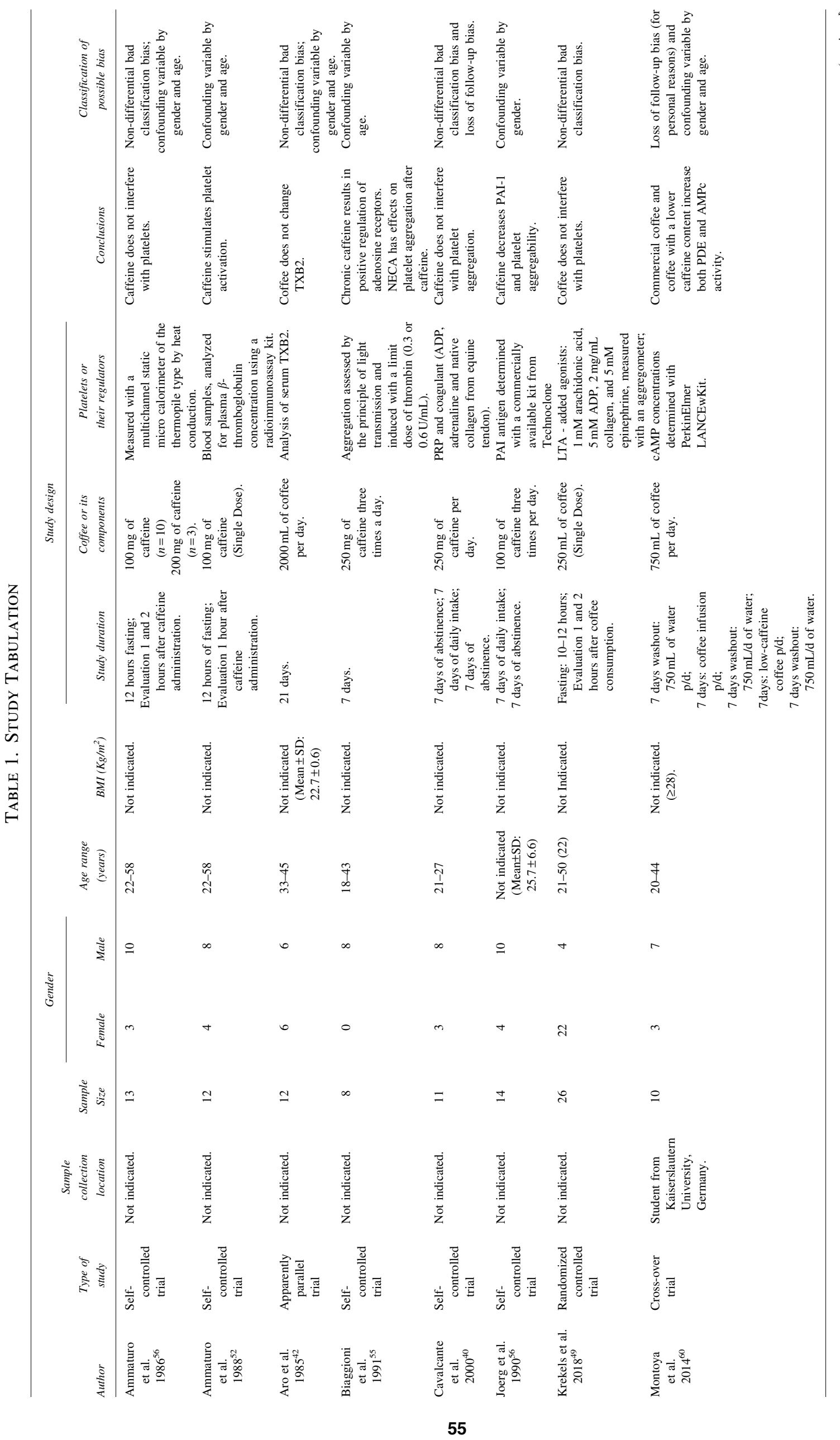




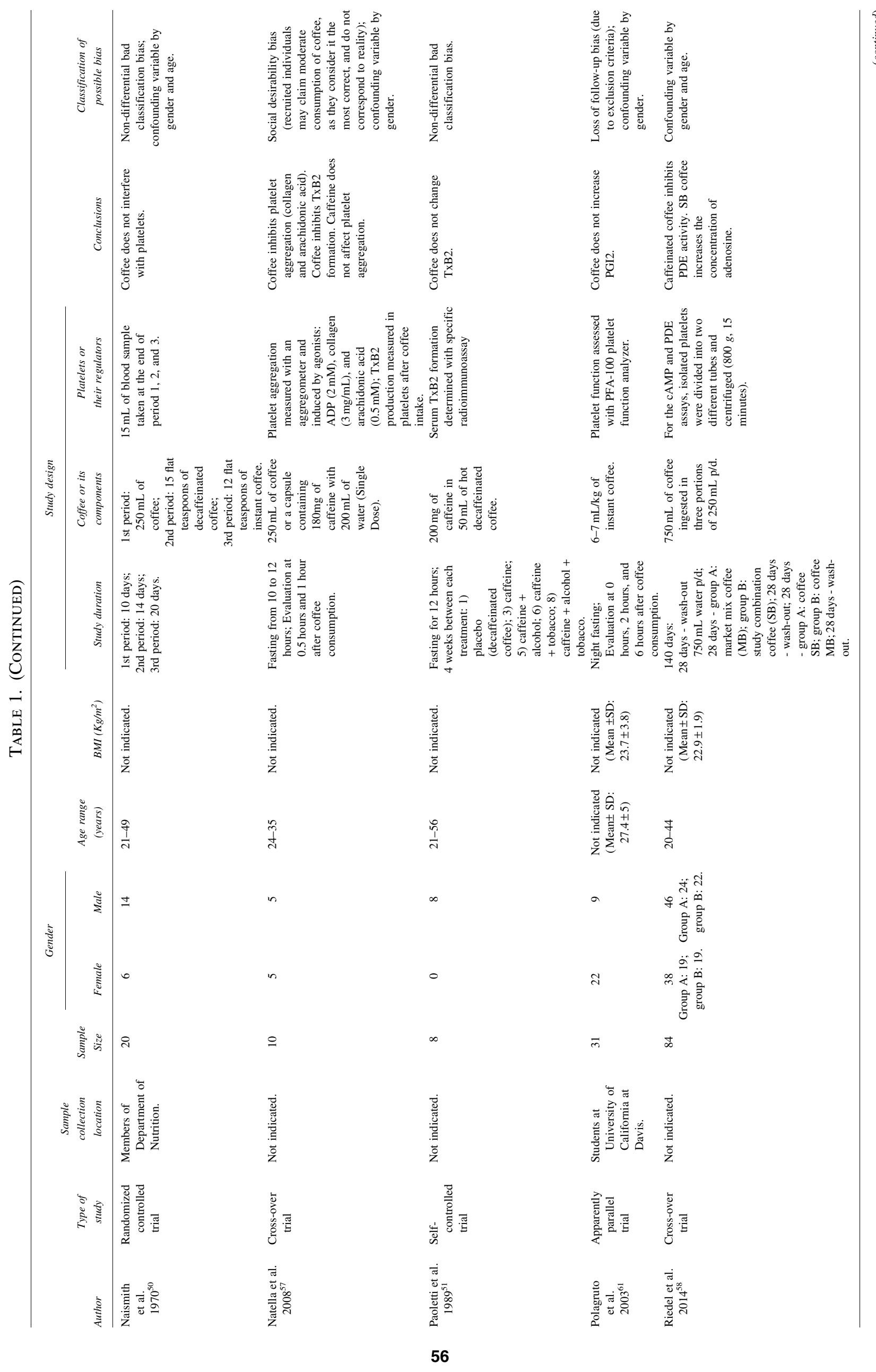




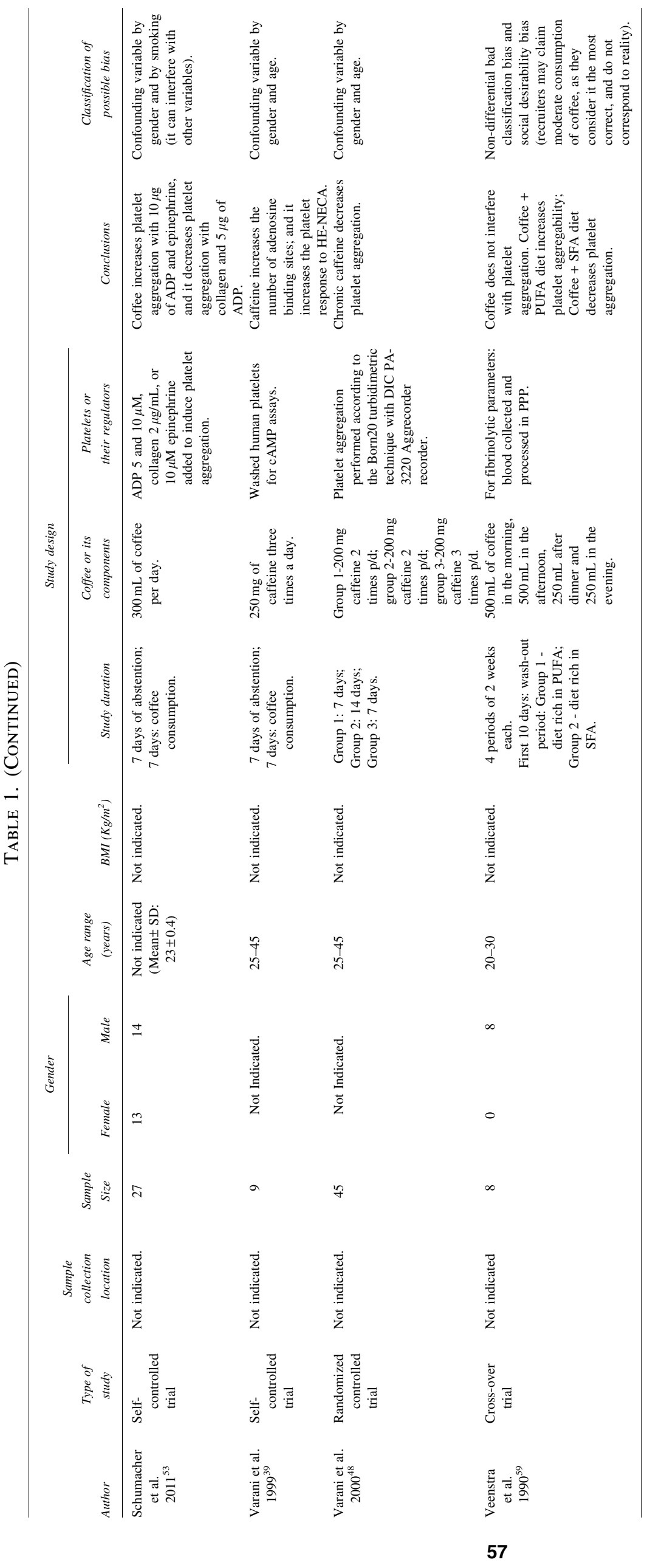


exclusion criteria, ${ }^{61}$ occurrence of adverse effects, ${ }^{40}$ or for personal reasons. ${ }^{60}$ One of the articles has an error in that there is no indication of the age range of its sample. ${ }^{49}$ In the remaining articles, no bias was identified, but confounding variables may exist, in relation to gender (female and male) and/or age (with significant differences in age groups).

Four articles mention coffee and prostanoids, ${ }^{42,51,57,61}$ two articles refer to coffee with PDE and cAMP, ${ }^{58,60}$ one of which also refers to the relationship between CGA and the PDE and CAMP ${ }^{60}$ only one of the articles relates coffee to the adenosine receptors, ${ }^{58}$ two refer to caffeine with the same, ${ }^{39,55}$ five articles focus on the relationship between coffee and platelets, ${ }^{49,50,53,57,59}$ seven focus on caffeine with platelets, ${ }^{40,48,50,52,54,56,57}$ only one of the articles speaks of the relationship between caffeine and PAI-1, ${ }^{56}$ and two report on caffeine with $5^{\prime}-\mathrm{N}$ ethylcarboxamidoadenosine (NECA). ${ }^{39,55}$

Although the articles did not report a gender difference in platelets, regarding coffee consumption, it is noteworthy that CYP1A2 is an isoenzyme involved in the metabolism of several drugs, including the N-hydroxylation of caffeine. ${ }^{63}$ There is less activity of cytochrome P450 Family 1 Subfamily A Member 2 (CYPIA2), in women compared with men, and the elimination of its substrates is significantly higher in men than in women. ${ }^{63}$

\section{Coffee and prostanoids}

From the studies observed, it was found that two ${ }^{42,51}$ concluded that there was no effect of coffee at the TXB2 level, that is, after a three-week treatment period with coffee ( 8 cups of coffee per day ${ }^{42}$ or $50 \mathrm{~mL}$ of hot decaffeinated coffee $\left.{ }^{51}\right)$ there were no changes in this prostanoid. However, another study ${ }^{57}$ reveals that after an acute consumption of $200 \mathrm{~mL}$ of American coffee, there was an inhibition of the formation of TXB2. ${ }^{57}$

Regarding PGI2, only one study ${ }^{61}$ focused on it, verifying that consuming coffee acutely there was no increase in this prostanoid. ${ }^{61}$

\section{Coffee, $P D E$, and $c A M P$}

One of the studies ${ }^{58}$ prepared three $250 \mathrm{~mL}$ portions of coffee for the participants to drink daily for four weeks, and this coffee with caffeine has been shown to inhibit PDE activity. ${ }^{58}$

On the other hand, in another experimental intervention, ${ }^{60}$ two types of coffee were prepared: commercial coffee with $618.1 \mathrm{mg} / \mathrm{L}$ and coffee with low caffeine content with $178.9 \mathrm{mg} / \mathrm{L}$, both for one week. Both coffees show an increase in PDE activity at the end of the intervention, despite variations occurring over the same period, ${ }^{60}$ as well as the cAMP level. ${ }^{60}$ It is indicated that both have $448 \mathrm{mg} / \mathrm{L}$ of CGA.

\section{Coffee and adenosine receptors}

Regarding adenosine, one of the studies ${ }^{58}$ prepared a type of coffee, which he called SB (study mixture), by mixing dark roasted coffee with portions of light roasted coffee, and taking that coffee, over four weeks, there was an increase in adenosine concentration. ${ }^{58}$

\section{Coffee and platelets}

One of the studies contemplated ${ }^{50}$ found that after a period 1 of 10 days, with a cup of coffee, and a period 2 of 14 days, with the intake of 15 flat teaspoons of decaffeinated coffee, coffee has not been shown to interfere with platelets. ${ }^{50}$ Two interventions ${ }^{49,59}$ indicate that the acute consumption of a cup of coffee, ${ }^{49}$ or six cups of coffee for two weeks, ${ }^{59}$ does not interfere with platelets or platelet aggregation.

Three studies ${ }^{53,57,59}$ point to coffee as an agent that can decrease/inhibit platelet aggregation, when it is induced by collagen and arachidonic acid (acutely consuming $200 \mathrm{~mL}$ of American coffee), ${ }^{57}$ collagen and $5 \mu \mathrm{g}$ of ADP (consuming $300 \mathrm{~mL}$ of chicory coffee for a week), ${ }^{53}$ or when it is consumed together with a diet rich in saturated fatty acids (SFA) for two weeks. ${ }^{59}$

However, two of the same studies referred to in the previous paragraph $^{53,59}$ show that coffee increases platelet aggregability, when it is induced by epinephrine and $10 \mu \mathrm{g}$ of ADP (consuming $300 \mathrm{~mL}$ of chicory coffee for a week), ${ }^{53}$ or when eaten together with a diet rich in polyunsaturated fatty acids (PUFA) for two weeks. ${ }^{59}$

\section{Caffeine and adenosine receptors}

Two interventions ${ }^{39,55}$ showed that consuming $250 \mathrm{mg}$ of caffeine, three times a day, for seven days, through the oral route, there was an increase in the binding sites of the adenosine receptor ${ }^{39}$ and their positive regulation. ${ }^{55}$

\section{Caffeine and PAI-1}

Only one of the analyzed authors ${ }^{56}$ looked at PAI-1, noting that after taking $100 \mathrm{mg}$ of caffeine three times a day for a week, there was a decrease in it. ${ }^{56}$

\section{Caffeine and platelets}

One of the authors ${ }^{52}$ demonstrated that with the acute intake of $100 \mathrm{mg}$ caffeine pill there was stimulation of platelet activation. $^{52}$

One of the interventions ${ }^{40}$ consisted of ingesting $250 \mathrm{mg}$ of caffeine in capsules for one week, checking that there is no relationship between caffeine and platelet aggregation. ${ }^{40}$ In another study, ${ }^{57} 180 \mathrm{mg}$ of caffeine was used to create caffeine capsules, consumed acutely, and it was found not to affect platelet aggregation. ${ }^{57}$ And with the same conclusion, after an acute consumption intervention $^{54}$ in which 10 individuals ingested a $100 \mathrm{mg}$ caffeine tablet, and only three individuals ingested a $200 \mathrm{mg}$ 
caffeine tablet, it was found that this substance did not interfere with platelets. ${ }^{54}$

On the other hand, in an intervention ${ }^{48}$ with ingestion of $200 \mathrm{mg}$ of caffeine orally, twice daily for two weeks, there was a decrease in platelet aggregability. ${ }^{48}$ Likewise, in a previously mentioned study, ${ }^{56}$ with the ingestion of $100 \mathrm{mg}$ of caffeine, three times a day, for a week, there was a decrease in platelet aggregability. ${ }^{56}$

\section{Caffeine and NECA}

Only two studies ${ }^{39,55}$ reported NECA, verifying that after ingesting $250 \mathrm{mg}$ of caffeine orally, three times a day, for seven days, there was an increase in platelet response to NECA,${ }^{39}$ and there were effects of the same on platelet aggregation. ${ }^{55}$

\section{$C G A, P D E$, and $C A M P$}

As previously mentioned, in one of the studies, ${ }^{60}$ two types of coffee were prepared: commercial coffee with $618.1 \mathrm{mg} / \mathrm{L}$ and coffee with low caffeine content with $178.9 \mathrm{mg} / \mathrm{L}$, both consumed for one week. Both show increased PDE activity, ${ }^{60}$ as well as the cAMP level ${ }^{60}$ and it is indicated that both have $448 \mathrm{mg} / \mathrm{L}$ of CGA. However, conclusions about this specific component of coffee are not drawn.

\section{Diterpenes}

This component of coffee is not evaluated in the articles contemplated for this systematic review, and results are not obtained for them.

\section{Discussion}

This review aims at understanding the effect of coffee or its components on platelets or their regulators. Three studies show no effects of coffee consumption on TXB2 and PGI2; likewise, four studies show no effects on platelets, with coffee/caffeine consumption. On the other hand, two studies show that after coffee consumption there is inhibition of TXB2 and PDE, five studies show that after coffee/caffeine consumption there is a decrease/inhibition of platelet aggregation or its components, and one of these reports that with caffeine the PAI-1 decreases. Four articles report an increase in platelet regulators such as PDE, cAMP, and adenosine with the consumption of coffee/caffeine. Two studies found an increase in platelet aggregation after coffee consumption, and three studies found that with caffeine consumption there was platelet stimulation and effects on it with the use of NECA. It should be noted that the heterogeneity of the studies, due to their different sample sizes, doses applied, duration of treatments, evaluation of results, and possible biases identified, may compromise the veracity of the results found.
In general, 10 articles do not find a relationship between coffee or its components and platelets and their regulators, 9 refer to associations that promote an increase in aggregation, and 8 talk about associations that promote a decrease in aggregation, which is why they are considered inconclusive results. This may be due to the different sample sizes, the presence of some types of bias, the absence of isolation of the coffee components in some studies, or the different doses of coffee/caffeine administered, as will be explained later.

\section{Coffee and prostanoids}

Two studies indicate that there is no effect on thromboxanes $^{42,51}$ after coffee consumption, whereas another one indicates an inhibition of their formation. ${ }^{57}$ TXA2 has an aggregating action and spontaneously transforms into TXB2. Intense platelet stimuli make the aggregation irreversible and agents such as TXA2 induce the cellular extrusion of substances accumulated in the platelet granules, called "release reaction." Thus, TXA2 is coresponsible, together with ADP, for the posterior growth of the hemostatic plug. ${ }^{36}$ The observed inhibitory effect can be explained if it is found that coffee is able to inhibit platelets, because if this occurs, the factors necessary for the production of TXA2 or its inactive form, TXB2, will not be released from the platelets. Regarding the studies that verify the lack of effect of coffee on thromboxanes, they may present a bad classification bias and it should be noted that the same occurred in the years 1985 and 1989, being, therefore, older in relation to the study that observes the inhibition of the formation of this regulator. Thus, there is a need for further studies in relation to thromboxanes and coffee.

Only one of the studies analyzed looked at PGI2 and was unable to verify the effect of coffee on it. ${ }^{61}$ PGI2 is released from vascular endothelial cells, producing vasodilation and inhibiting platelet aggregation, which allows to counterbalance the actions of TXA2. ${ }^{64}$ The conclusion obtained may be due to the type of intervention performed, since there was no isolation of coffee, to specifically study this drink in the action of PGI2, and also due to loss of follow-up, reducing the sample size. For more assertive conclusions, it would be useful to conduct a study focusing on coffee or its components and the relationship with the regulator in question.

\section{Coffee, $P D E$, and $C A M P$}

One of the studies ${ }^{58}$ demonstrates that after the consumption of coffee, there was an inhibition of PDE activity, which, by not performing its hydrolysis function, will promote an increase in the concentration of cAMP, which may be related to the inhibition of platelet aggregation. PDEs are enzymes that are responsible for the degradation of cyclic nucleotides in the cell, which leads to an increase in intracellular concentrations of 
cAMP and cyclic 3'5' -guanosine monophosphate (cyclic GMP or GMPc). ${ }^{65}$ Methylxanthines, such as caffeine, prevent the conversion of CAMP to AMP, acting as PDE inhibitors, increasing the inhibitory effects of adenosine on platelet aggregation. ${ }^{66}$ In this way, it could be concluded that coffee influences the modulation of platelet aggregation, and, consequently, decreases platelet count. However, this study contemplates coffee with caffeine, so the verified effect may be due to coffee as a whole, or to one of its specific components.

The same is true for the other study ${ }^{60}$ that prepared commercial coffee and coffee with a low caffeine content. Both verified an increase in the activity of PDE and cAMP; however, throughout the intervention, the inhibition of activity and its subsequent increase were verified. The presence of the same amount of CGA in both drinks with different caffeine content may explain the variations in results throughout the experience, as well as the loss of follow-up (loss of two people for personal reasons). ${ }^{60}$ For further clarification on the real effect of coffee on PDE and cAMP, as well as the consequent effect on platelet aggregation and counting, the isolation of the different components of coffee and the observation of their effect on platelets could be made.

\section{Coffee and adenosine receptors}

One of the contemplated studies ${ }^{58}$ notes that the coffee mixture (SB) that was created in the experiment causes an increase in adenosine concentrations. By doing so, one may be stimulating an increase in the production of cAMP by platelets, which will lead to inhibition of platelet aggregation, that is, a decrease in platelet count. Of the five subtypes of adenosine receptors, ${ }^{33,48}$ A2A was identified as being specifically expressed in platelets. $^{33,39}$ Both $\mathrm{A} 2$ adenosine receptors (A2A and A2B) lead to stimulation of adenyl cyclase and consequent elevation of $\mathrm{cAMP} .{ }^{33}$ For the intervention carried out, the different degrees of roasting used to create this coffee mixture may be the reason for this conclusion, as well as the different components of the coffee. As such, further studies with this type of mixture should be performed for more solid conclusions.

\section{Coffee and platelets}

Three studies refer to the lack of relationship between coffee and platelets; however, two of them are old studies, $1990^{59}$ and $1970,{ }^{50}$ which may reveal a lack of updating of information relevant to the performance of the experiment and bias of bad non-differential classification. Among them, the most recent study dates back to 2018 and states the same as the previous ones; however, it can also show bias of non-differential classification and only studies the effect of drinking a cup of coffee, ${ }^{49}$ with acute ingestion being not possible enough to detect some kind of relationship. To this end, the study of chronic cof- fee consumption would be conducive to obtaining more credible information in establishing a relationship with another component.

One of the included studies presents the inhibition of platelet aggregation induced by arachidonic acid after coffee consumption, ${ }^{57}$ and the literature reports that arachidonic acid is the main substrate for the synthesis of eicosanoids, inflammatory mediators of lipid origin, exercising control in platelet aggregation. ${ }^{67}$ The consumption of coffee on this type of inducer may cause inhibition of platelet aggregation. The same study indicates a decrease in platelet aggregation after coffee consumption, when it is induced by collagen. ${ }^{57}$ When administered eicosapentaenoic acid (EPA), there is a reduction in the response of platelets to collagen ${ }^{68}$; so, depending on the type of diet, the response that platelets give to their cascade regulators may be altered, which may cause a decrease in platelet aggregability.

One of the studies analyzed shows the decreased effect on platelets when coffee is consumed together with a diet rich in SFA. ${ }^{59}$ The intake of diets rich in SFA is discouraged by both the increase in LDL cholesterol and the increased risk of cardiovascular disease. The fact that they predispose to thrombosis can lead to altered platelet aggregation. ${ }^{69}$ Together with coffee, it may be possible to observe a decrease in this effect on platelets; however, further studies should be performed for better clarification.

ADP is relatively weak as a platelet stimulator, ${ }^{70}$ so the inhibitory effect of coffee on platelet aggregation, ${ }^{53}$ when it is induced by $5 \mu \mathrm{g}$ of ADP, can be explained by the weak stimulation that this regulator has. On the other hand, the same study finds that after coffee consumption there is an increase in platelet aggregation, when it is induced by $10 \mu \mathrm{g}$ of ADP. ${ }^{53}$ Possibly the increase in the concentration of this regulator associated with the consumption of a stimulant, such as coffee, may cause platelet aggregation.

In one of the studies contemplated, it appears that there is an increase in platelet aggregability when it is induced by epinephrine. ${ }^{53}$ Epinephrine, or adrenaline, is also one of the regulators of platelet aggregation, known to be relatively weak as a platelet stimulator. ${ }^{70}$ However, the effect obtained may be due to the consumption of coffee during the test, becoming responsible for the increase in aggregation.

Regarding regulators, one of the studies reported an increase in platelet aggregation when coffee was consumed together with a diet rich in PUFA. ${ }^{59}$ According to the literature, it is known that omega-3 fatty acids comprised docosahexaenoic acid (DHA) and EPA of marine origin, and $\alpha$-linolenic acid (ALA) of plant origin. Among its physiological and metabolic effects is the decrease in platelet aggregation. ${ }^{67,71}$ This effect is contradicted in this analysis, perhaps due to the joint consumption of the diet rich in PUFA with coffee, or because it may 
present biases of poor non-differential classification and social desirability. New studies analyzing the same variables should be carried out to better interpret the results.

\section{Caffeine and adenosine receptors}

Two of the included studies observed an increase in the binding sites of the adenosine receptors, ${ }^{39}$ as well as their positive supra-regulation. ${ }^{55}$ However, methylxanthines, such as caffeine, are non-selective blockers of the adenosine receptor, ${ }^{33}$ a purine released locally that acts on different receptors. The result obtained may be because both studies are old, that is, 1999 and 1991, respectively. In addition, both studies included a small number of participants, 9 and 8 individuals, respectively. For more consistent results, it would be necessary to conduct studies with a larger number of participants.

\section{Caffeine and PAI-1}

One of the studies analyzed found a decrease in PAI-1 after taking caffeine. ${ }^{56}$ PAI-1 is a fast-acting fibrinolysis inhibitor that acts on the regulation of plasmin activity, through the formation of complexes that inactivate tissue plasminogen activator (t-PA) and urokinase type plasminogen activator (u-PA), controlling plasminogen activation ${ }^{72,73}$ Fibrinolysis is the process by which the fibrin clot is destroyed and, since fibrin functions as a grid that allows the maintenance of the platelet aggregation structure, in the event of an injury, it is necessary to control its maintenance process. ${ }^{70}$ The fact that PAI-1 is decreased with the consumption of caffeine can cause a decrease in platelet aggregability, because the regulator will not be as able to inhibit fibrinolysis.

\section{Caffeine and platelets}

One of the authors verified platelet activation after consuming $100 \mathrm{mg}$ of caffeine in a pill. ${ }^{52}$ Caffeine is known to be a stimulating substance, which acts on the body by blocking adenosine receptors, manifesting itself by an increase in catecholamine secretion: adrenaline, dopamine, and serotonin. With the consumption of caffeine, there is stimulation of the central nervous system, increased heart rate, and dilation of blood vessels. ${ }^{74-77}$ Vasodilation causes redness, pain, and heat in the region; so platelets, which are located on the periphery of blood vessels, perform non-hemostatic functions, controlling inflammation and wound healing. ${ }^{78}$ In the event of an injury, platelets perform hemostatic functions, helping to repair the vascular injury and preventing the occurrence of bleeding by participating in the formation of the primary hemostatic plug. That is, in some way, caffeine may be associated with platelet activation, one of the stages of platelet metabolism.

Three studies ${ }^{40,54,57}$ did not find a relationship between caffeine and platelet aggregability, which may present a non-differential bias. These results may also be due to the age of the articles dating from $1986^{54}$ to $2000,{ }^{40}$ as well as the inclusion of a sample of only 13 individuals in both. Another reason may be to perform the test in an acute manner, ${ }^{57}$ an aspect that may not provide enough time for the interaction of caffeine with platelets. More recent trials that promote chronic caffeine consumption will be needed to obtain more illuminating results.

On the other hand, two studies ${ }^{48,56}$ point to decreased platelet aggregation when consuming caffeine, and in both cases this substance is chronically ingested for one $^{56}$ and two ${ }^{48}$ weeks, respectively. One of these studies ${ }^{48}$ even uses a sample of 45 healthy individuals, contributing to a large sample size, which can support the veracity of the results obtained. In this way, different experiments with a large sample size should be performed to confirm or refute the observed results.

\section{Caffeine and NECA}

Both studies that focused on NECA indicated increased platelet response to this regulator, ${ }^{39}$ and its effects on platelet aggregation. ${ }^{55}$ However, according to the literature, NECA is an adenosine analogue that is 22,900 times more potent than this as a vasodilator, which is responsible for inhibiting human platelet aggregation induced by ADP, adrenaline, 5-hydroxytryptamine (5 HT), and thrombin. ${ }^{79}$ One of the studies ${ }^{55}$ reports the effect of NECA on platelet aggregation, but it does not clarify whether it is at the level of inhibition of aggregation or stimulation. The increase in platelet response seen in the other study ${ }^{39}$ may occur due to caffeine stimulation over the NECA regulator. For better clarification, further studies should focus on the relationship between caffeine and NECA and the effect on platelets.

\section{$C G A, P D E$, and $C A M P$}

In the study ${ }^{60}$ that indicates an increase in PDE and cAMP, the results observed may be due to loss of followup (excluding two individuals), or to the similar CGA content in both studied coffees. CGA is a group of phenolic compounds formed from the esterification of quinic acid with some derivatives of cinnamic acid (caffeic, ferulic, and p-cumaric acid) ${ }^{80}$ However, the observed effect can also be associated with the degree of roasting or the coffee species used in the experiment, since the CGA content of a cup of coffee will depend mainly on these factors (70-350 mg per $200 \mathrm{~mL}$ of drink) ${ }^{80}$ As such, further studies are needed to isolate the CGA and verify its effect on the PDE and, consequently, cAMP.

\section{Diterpenes}

This component of coffee is not evaluated by the articles included in this systematic review, and no results are obtained for it.

Limitations: This review article may have some limitations, such as the lack of data regarding the sample collection location, age group, or classification as to the type of 
study, considering the lack of information that some of the included articles presented. One of the limitations of this article is related to the high heterogeneity found, due to various regimens, doses, duration, and other factors previously described at the different intervention periods. As previously mentioned, most studies present possible bias or confounding variables, so the results obtained may be conditioned in this way. Likewise, there are variables with a few studies focusing on them, such as at the level of NECA and PAI-1, which may limit the conclusions to be drawn about them. The incongruity of the results found is also a limitation, because did not have a specific conclusion on the relationship between coffee or its components with platelets and their regulators.

\section{Conclusion}

Conclusively, there are results that do not corroborate each other. However, there seems to be a relationship between coffee/caffeine consumption on platelets and their regulators. The inhibition or promotion of platelet aggregation may depend on the type of coffee component, the beverage as a whole, the type of agonist used to induce aggregation, joint consumption with other foods, or other factors such as age and gender.

In short, consistent data are not obtained in the conclusion drawn, so further studies should be carried out, individualizing the components of the coffee during a chronic consumption, allowing to verify the effect on the platelets or their regulators. They should also consider a significant sample size and consider the differences that may result from the age and/or gender of the participants.

\section{Authorship Confirmation Statement}

L.S.S.G. conducted the research in the databases, selecting and analyzing the articles included. She wrote the entire article.

J.A.S. designed the study, defined the methodology, interpreted the results, reviewed, and approved the final version of the article.

J.V. gave technical support to the theoretical framework linked to the platelets, reviewed, and approved the final version of the article.

This systematic review article has never been published earlier and has not been, nor will be, submitted elsewhere while under consideration for publication by the Journal of Caffeine and Adenosine Research.

\section{Author Disclosure Statement}

No competing financial interests exist. The authors declare that this article was written as part of the final evaluation of the BSc studies in Dietetics and Nutrition by L.S.S.G.

\section{Funding Information}

The Centro de Investigação de Montanha (CIMO) received financial support from Fundação para Ciencia e a
Tecnologia (FCT, Portugal) and from Fundo Europeu de Desenvolvimento Regional (FEDER), under PT2020 program (UIDB/00690/2020).

\section{Supplementary Material}

Supplementary File S1

Supplementary File S2

\section{References}

1. Montagnana M, Favaloro EJ, Lippi G. Coffee intake and cardiovascular disease: Virtue does not take center stage. Semin Thromb Hemost. 2012;38:164-177.

2. Ramalakshmi K, Raghavan B. Caffeine in coffee: Its removal. Why and how? Crit Rev Food Sci Nutr. 1999;39: 441-456.

3. Nawrot P, Jordan S, Eastwood J, et al. Effects of caffeine on human health. Food Addit Contam. 2003;0:1-30.

4. Nehlig A. Interindividual differences in caffeine metabolism and factors driving caffeine consumption. Pharmacol Rev. 2018;70:384-411.

5. Kolahdouzan M, Hamadeh MJ. The neuroprotective effects of caffeine in neurodegenerative diseases. CNS Neurosci Ther. 2017;23:272-290.

6. Karunanidhi A, Thomas R, Van Belkum A, et al. In vitro antibacterial and antibiofilm activities of chlorogenic acid against clinical isolates of stenotrophomonas maltophilia including the trimethoprim/sulfamethoxazole resistant strain. Biomed Res Int. 2013;2013:392058.

7. Meng S, Cao J, Feng Q, et al. Roles of chlorogenic acid on regulating glucose and lipids metabolism: A review. Evid Based Complement Alternat Med. 2013;2013:801457.

8. Hwang SJ, Kim YW, Park Y, et al. Anti-inflammatory effects of chlorogenic acid in lipopolysaccharide- stimulated RAW 264.7 cells. Inflamm Res. 2014;63:81-90.

9. Amin RP, Kunaparaju N, Kumar S, et al. Structure elucidation and inhibitory effects on human platelet aggregation of chlorogenic acid from Wrightia tinctoria. J Complement Integr Med. 2013 [Epub ahead of print]; DOI: 10.1515/jcim-2012-0048.

10. Bijak M, Saluk J, Ponczek MB, et al. Antithrombin effect of polyphenol-rich extracts from black chokeberry and grape seeds. Phyther Res. 2013;27:71-76.

11. Olthof MR, Hollman PCH, Katan MB. Chlorogenic acid and caffeic acid are absorbed in humans. J Nutr. 2001; 131:66-71.

12. Nardini M, Cirillo E, Natella F, et al. Absorption of phenolic acids in humans after coffee consumption. J Agric Food Chem. 2002;50:5735-5741.

13. Kurzrock T, Speer K. Diterpenes and diterpene esters in coffee. Food Rev Int. 2001;17:433-450.

14. Urgert R, van der Weg G, Kosmeijer-Schuil TG, et al. Levels of the cholesterol-elevating diterpenes cafestol and kahweol in various coffee brews. J Agric Food Chem. 1995;43:2167-2172.

15. de Lima FA, Sant'ana AEG, Ataíde TDR, et al. Café e saúde humana: Um enfoque nas substâncias presentes na bebida relacionadas às doenças cardiovasculares 1 . Rev Nutr. 2010;23:1063-1073.

16. Oñatibia-Astibia A, Franco R, Martínez-Pinilla E. Health benefits of methylxanthines in neurodegenerative diseases. Mol Nutr Food Res. 2017;61:1-44. 
17. Harpaz E, Tamir S, Weinstein A, et al. The effect of caffeine on energy balance. J Basic Clin Physiol Pharmacol. 2017;28:1-10.

18. Gan Y, Wu J, Zhang S, et al. Association of coffee consumption with risk of colorectal cancer: A meta-analysis of prospective cohort studies. Oncotarget. 2017;8: 18699-18711.

19. Ruxton $\mathrm{CH}$. The impact of caffeine on mood, cognitive function, performance and hydration: A review of benefits and risks. Br Nutr Found. 2008;33:15-25.

20. Wilhelmus MMM, Hay JL, Zuiker RGJA, et al. Effects of a single, oral $60 \mathrm{mg}$ caffeine dose on attention in healthy adult subjects. J Psychopharmacol. 2017;31: 222-232.

21. Arab L. Epidemiologic evidence on coffee and cancer. Nutr Cancer. 2010;62:271-283.

22. Senda Nakagawa H, Ito H, Hosono S, et al. Coffee consumption and the risk of colorectal cancer by anatomical subsite in Japan: Results from the HERPACC studies. Int J Cancer. 2017;141:298-308.

23. Ding M, Bhupathiraju S, Satija A, et al. Long-term coffee consumption and risk of cardiovascular disease: A systematic review and a dose-response meta- analysis of prospective cohort studies. Natl Institutes Heal. 2014;129:643-659.

24. Heaney RP. Effects of caffeine on bone and the calcium economy. Food Chem Toxicol. 2002;40:1263-1270.

25. James JE, Kristjánsson ÁL, Sigfúsdóttir ID. Adolescent substance use, sleep, and academic achievement: Evidence of harm due to caffeine. J Adolesc. 2011;34:665-673.

26. Weng X, Odouli R, Li DK. Maternal caffeine consumption during pregnancy and the risk of miscarriage: A prospective cohort study. Am J Obstet Gynecol. 2008;198: 279.e1-e279.e8.

27. Wachamo HL. Review on health benefit and risk of coffee consumption. Med Aromat Plants. 2017;6:4.

28. Echeverri D, Pizano A, Montes FR, et al. Acute effect of coffee consumption on arterial stiffness, evaluated using an oscillometric method. Artery Res. 2017;17:16-32.

29. Sofi F, Conti AA, Gori AM, et al. Coffee consumption and risk of coronary heart disease: A meta-analysis. Nutr Metab Cardiovasc Dis. 2007;17:209-223.

30. Chang HH, Lo SJ. Full-spreading platelets induced by the recombinant rhodostomin are via binding to integrins and correlated with FAK phosphorylation. Toxicon. 1998;36:1087-1099.

31. Koupenova M, Clancy L, Corkrey H, et al. Circulating platelets as mediators of immunity, inflammation and thrombosis. Circ Res. 2018;122:337-351.

32. Vieira-de-Abreu A, Campbell RA, Weyrich AS, et al. Platelets: Versatile effector cells in hemostasis, inflammation, and the immune continuum. Semin Immunopathol. 2012;34:5-30.

33. Santhakumar AB, Fozzard N, Perkins AV, et al. The synergistic effect of taurine and caffeine on platelet activity and hemostatic function. Food Public Heal. 2013;3:147-153.

34. Middleton E, Rondina MT. Platelets in infectious disease. Hematology. 2016;2016:256-261.

35. McEwen BJ. The influence of diet and nutrients on platelet function. Semin Thromb Hemost. 2014;40:214-226.

36. Armaganijan D. Editorial Ativação Plaquetária nas Formas Distintas da Doença Arterial. Arq Bras Cardiol 2006;87:401-402.
37. Paramothayan NS, lasserson TJ, Wells A, et al. Prostacyclin for pulmonary hypertension in adults (Review). Cochrane Database Syst Rev. 2005; 2005: CD002994.

38. Lima LM, Carvalho M das G, Fonseca Neto CP, et al. Associação de níveis plasmáticos de PAI-1 e polimorfismo $4 \mathrm{G} / 5 \mathrm{G}$ em pacientes com doença arterial coronariana. Arq Bras Cardiol. 2011;97:462-489.

39. Varani K, Portaluppi F, Merighi S, et al. Caffeine alters $\mathrm{A}(2 \mathrm{~A})$ adenosine receptors and their function in human platelets. Circulation. 1999;99:2499-2502.

40. Cavalcante JWS, Santos Jr. PRM, Menezes MGF de, et al. Influence of caffeine on blood pressure and platelet aggregation. Arq Bras Cardiol. 2000;75:97-105.

41. Fuentes E, Caballero J, Alarcón M, et al. Chlorogenic acid inhibits human platelet activation and thrombus formation. PLoS One. 2014;9:e90699.

42. Aro A, Kostiainen E, Huttunen JK, et al. Effects of coffee and tea on lipoproteins and prostanoids. Atherosclerosis. 1985;57:123-128.

43. Principais itens para relatar Revisões sistemáticas e Meta-análises: A recomendação PRISMA. Epidemiol Servi Saúde. 2015;4:2.

44. Moher D, Liberati A, Tetzlaff J AD. Preferred reporting items for systematic reviews and meta-analyses: The PRISMA Statement. PLoS Med. 2009;6:e1000097.

45. Selcuk AA. A Guide for Systematic Reviews: PRISMA. Turkish Arch Otorhinolaryngol. 2019;57:57-58.

46. Aslam S, Emmanuel P. Formulating a researchable question: A critical step for facilitating good clinical research. Indian J Sex Transm Dis. 2010;31:47-50.

47. Page MJ, McKenzie JE, Bossuyt PM, et al. The PRISMA 2020 statement: an updated guideline for reporting systematic reviews. Syst Rev. 2021;10:89.

48. Varani K, Portaluppi F, Gessi S, et al. Dose and time effects of caffeine intake on human platelet adenosine $\mathrm{A}(2 \mathrm{~A})$ receptors: Functional and biochemical aspects. Circulation. 2000;102:285-289.

49. Krekels JPM, Verhezen PWM, Henskens YMC. Platelet Aggregation in Healthy Participants is Not Affected by Smoking, Drinking Coffee, Consuming a High-Fat Meal, or Performing Physical Exercise. Clin Appl Thromb Hemost. 2019:25:1076029618782445.

50. Naismith DJ, Akinyanju PA, Szanto S, et al. The effect in volunteers of coffee and decaffeinated coffee on blood glucose, insulin, plasma lipids and some factors involved in blood clotting. Ann Nutr Metab. 1970;12:144-151.

51. Paoletti R, Corsini A, Tremoli E, et al. Effects of coffee on plasma lipids, lipoproteins and apolipoproteins. Pharmacol Res. 1989;21:27-38.

52. Ammaturo V, Perricone C, Canazio A, et al. Caffeine stimulates in vivo platelet reactivity. Acta Med Scand. 1988;224:245-247.

53. Schumacher E, Vigh É, Molnár V, et al. Thrombosis preventive potential of chicory coffee consumption: A clinical study. Phyther Res. 2011;25:744-748.

54. Ammaturo V, Monti M. Caffeine stimulates in vivo overall cell metabolism: Microcalorimetric measurement of heat production in human platelets. Acta Med Scand. 1986;220:181-184.

55. Biaggioni I, Paul S, Puckett A, et al. Caffeine and theophylline as adenosine receptor antagonists in humans. J Pharmacol Exp Ther. 1991;258:588-593. 
56. Joerg M, Huber K, Peska M, et al. Effect of caffeine intake on platelet antigen levels of plasminogen activator inhibitor-1 (PAI-1). Fibrinolysis. 1990;4:71-73.

57. Natella F, Nardini M, Belelli F, et al. Effect of coffee drinking on platelets: Inhibition of aggregation and phenols incorporation. Br J Nutr. 2008;100:1276-1282.

58. Riedel A, Dieminger N, Bakuradze T, et al. A 4-week consumption of medium roast and dark roast coffees affects parameters of energy status in healthy subjects. Food Res Int. 2014;63:409-419.

59. Veenstra J, Kluft C, Ockhuizen T, et al. Effects of four days of moderate wine and coffee consumption on fibrinolysis and platelet aggregation. Fibrinolysis Proteolysis. 1990;4:4.

60. Montoya GA, Bakuradze T, Eirich M, et al. Modulation of $3^{\prime}, 5^{\prime}$-cyclic AMP homeostasis in human platelets by coffee and individual coffee constituents. Br J Nutr. 2014;112:1427-1437.

61. Polagruto JA, Schramm DD, Wang-Polagruto JF, et al. Effects of flavonoid-rich beverages on prostacyclin synthesis in humans and human aortic endothelial cells: Association with ex vivo platelet function. J Med Food. 2003;6:301-308.

62. Botelho F, Silva C, Cruz F. Epidemiologia Explicada Viéses. Acta Urol. 2010;3:47-52.

63. Costa VM, Bastos MDL, Carvalho F. Género masculino vs feminino: Factor relevante para as respostas farmacológicas e efeitos adversos de fármacos? Acta Farm Port. 2011;1:55-64.

64. Manrique R. Antiagregantes plaquetários. ... Int sobre Ateroscler Coronária (ed 4) ... 1979;XIV:21-27.

65. Campos H. Inibidores de fosfodiesterases: Novas perspectivas de uma antiga terapia na asma? * Phosphodiesterase inhibitors: New perspectives on an old therapy for asthma?. J Pneumologia. 2003;29:405-412.

66. Mills DC, Smith JB. The influence on platelet aggregation of drugs that affect the accumulation of adenosine 3':5'-cyclic monophosphate in platelets. Biochem J. 1971;121:185-196.

67. Perini JÂ de L, Stevanato FB, Sargi SC, et al. Ácidos graxos poli-insaturados n-3 e n-6: Metabolismo em mamíferos e resposta imune. Rev Nutr. 2010;23:10751086.

68. Castro A. Influencia Dos Ácidos Gordos Omega-3 Do Peixe Na. Inst Super Ciências da Nutr da Univ do Porto; $1-41$.
69. Chaveiro N. Bioacessibilidade de ácidos gordos em salmão e corvina de aquacultura. Eng Aliment - Process Aliment. 2012;1-111.

70. Leung L. Hematology: Hemostasis and its Regulation. In Dale D and Federman D. ACP Medicine. 3rd Edition: McGraw Hill. 2007.

71. Brasileira S. I Diretriz sobre o consumo de gorduras e saúde cardiovascular. Arq Bras Cardiol. 2013;100:1-40.

72. Szymanski LM, Pate RR, Durstine JL. Effects of maximal exercise and venous occlusion on fibrinolytic activity in physically active and inactive men. J Appl Physiol. 1994;77:2305-2310.

73. Kohler H, Grant P. Plasminogen-activator inhibitor type 1 and coronary artery disease. N Engl J Med. 2000;342: 1792-1801.

74. Babu KM, Church RJ, Lewander W. Energy drinks: The new eye-opener for adolescents. Clin Pediatr Emerg Med. 2008;9:35-42.

75. Glade MJ. Caffeine-Not just a stimulant. Nutrition. 2010;26:932-938.

76. Reissig CJ, Strain EC, Griffiths RR. Caffeinated energy drinks-A growing problem. Drug Alcohol Depend. 2009;99:1-10.

77. Satel S. Is caffeine addictive? - A review of the literature. Am J Drug Alcohol Abuse. 2006;32:493-502.

78. Cocco R. Metabolismo das plaquetas. Semin apresentado na Discip Bioquímica do Tecido Anim Programa Pós-Graduação em Ciências Veterinárias. 2016;1-7.

79. Cusack NJ, Hourani SMO. 5'-N-Ethylcarboxamidoadenosine: A Potent Inhibitor of Human Platelet Aggregation. Br J Pharmacol. 1981;72:443-447.

80. Clifford MN. Chlorogenic acids and other cinnamates nature, occurrence and dietary burden. J Sci Food Agric. 1999;79:362-372.

Address correspondence to: Liliana Sofia da Silva Gache, BSc Escola Superior de Saúde com sede no Instituto Politécnico de Bragança Campus de Santa Apolónia Bragança 5300-253 Portugal

E-mail: 1ssg19@gmail.com 